Macedonian Pharmaceutical Bulletin, 66 (Suppl 1) 61 - 62 (2020)

Online ISSN 1857 - 8969

UDC: $615: 658.1 / .5(438)$

DOI: $10.33320 /$ maced.pharm.bull.2020.66.03.030

Short communication

\title{
National medicines policy in Poland - pharmacoeconomic and IT solutions
}

\author{
Marcin Czech
}

Department of Pharmacoeconomics, Institute of Mother and Child, Kasprzaka str. 17A, 01-211 Warszaw, Poland

\section{Introduction}

Pursuant to Art. 68 of the Polish Constitution, everyone has the right to have their health protected and the state is obliged to ensure equal access to healthcare services financed from public funds to all citizens. For the first time in many years, the Polish government has decided to treat health care as its priority. It has been recently decided by the government to increase spending on health care to $6 \%$ of GDP in 2024. The planned nearly two-fold increase in healthcare expenditure is a historic moment. The goal now is to make the most efficient use of the money to secure tangible benefits for patients and help satisfy the health needs of citizens in the best possible way.

The role of decision makers is to ensure an efficient healthcare system which will facilitate the prevention of diseases and provide the best care and pharmacological treatment to those who are already ill.

\section{Materials and methods}

"National Medicines Policy in Poland 2018-22" was drafted on the basis of the 2016 guidelines of the World Health Organizations on how to develop and implement national drug policies (WHO, 2016). It lays down mid-term and long-term goals set for pharmaceutical market participants and decision makers and identifies the main tools required to achieve them. The document was developed in the course of a structured process of consultations with all stakeholders. The following parties took part in the creation of this document: representatives of the public sector, including the Ministry of Health (coordinator of the process); Ministry of Entrepreneurship and Technology; Ministry of Finance; Ministry of Family, Labour and Social Policy; National Health Fund; Agency for Health Technology Assessment and Tariff System; Chief Pharmaceutical Inspector; Chief Sanitary Inspector; National Medicines Institute; National Health Institute; and the Office for Registration of Medicinal Products, Medical Devices and Biocidal Products; MPs and senators who are members of parliamentary Health Committees; representatives of patients' organizations; associations of pharmaceutical industry manufacturers and employers, and self-governing authorities of the medical professions. The objectives of the National Medicines Policy are consistent with the Commission on Essential Medicines Policies published in 2017 (Wirtz et al., 2017). In each of the covered areas, the document provides a description of the status quo, a diagnosis and description of the characteristics of the key challenges. It also sets the objectives and describes the tools required to achieve them as well as the methods of performance measurement. Additionally, it addresses the need to strengthen the position of the pharmaceutical industry based in Poland and the special role of the

\footnotetext{
* marcin.czech@imid.med.pl
} 
e-health system in the future. In view of the growing importance of prophylaxis and the need to prevent diseases, it also includes primary prevention section. The document was reviewed by WHO.

\section{Results and discussion}

The National Medicines Policy is a strategic document, which sets out the priorities of the Government of the Republic of Poland regarding the management of medicines between 2018 and 2022 . It also responds to the expectations of various stakeholders to set forth the framework and directions for medicines management.

Patients should have access to medicines with proven efficacy, quality and safety for the prevention and treatment of diseases, both in inpatient and outpatient settings. At the same time, in order to ensure sound management, medicines financed from public funds should meet the requirements of costeffectiveness and their financing must be within the current limits of the payer's budget according to pharmacoeconomic principles. The objective is to increase the accessibility of medicines in order to satisfy the health needs of patients to the greatest extent possible. This goal can be achieved via a methodical increase in the number of cost-effective and affordable medicines and a reduction in the patients' co-payments as well as by speeding up the time to market of new medicines.

Reimbursement decisions under which medicines are co-funded from public sources are made on the basis of epidemiological and demographic data and public health needs, within a transparent decision-making process. From the social perspective, population groups which require special attention include children, pregnant women, persons with disabilities and seniors. The Medicines

Policy is informed by scientific evidence and reliable data, in particular concerning such aspects as mortality, morbidity and prevalence, risks, medicine efficacy, safety, quality and cost-effectiveness, demographics, productivity, incapacity for work, disability, costs and micro- and macro-economic indicators.
Poland supports measures aimed at enhancing the competitiveness and innovativeness of the pharmaceutical industry by encouraging research and development of new medicines, improving the conditions for conducting clinical trials, increasing the production capacity in Poland, fostering export sales and facilitating international expansion.

The National Medicines Policy should be implemented through adopted legislation and pursued by the competent public authorities. The goals will be regularly reviewed, both in terms of the impact on the general population's health and on the national economy.

\section{Conclusion}

The guidelines of the World Health Organizations create an excellent framework for the development of strategic state documents covering medicines management. The Medicines Policy should always be an integral element of country's health policy.

\section{Acknowledgements}

I would like to thank all persons who have contributed to the development of the Policy: Jakub Adamski, Artur Falek, Anna Lech, Iga Lipska, Iwona Skrzekowska- Baran, Rafal Zysk.

\section{References}

file:///C:/Users/Marcin\%20Czech/Downloads/POLITYK A_LEKOWA_PAN 2018-2022_v92FF\% 20(2).pdf (Last accessed: 21 March, 2020).

Wirtz, V.J., Hogerzeil, H.V., Gray, A.L., Bigdeli, M., Joncheere, C.P., Ewen, M.A., 2017. Essential medicines for universal health coverage. Report of the Lancet Commission on essential medicines policies. The Lancet 389, 403-476.

World Health Organization, 2016. How to develop and implement a national drug policy. Second edition, Geneva. Switzerland. Available at:

http://apps. who.int/medicinedocs/pdf/s2283e/s2283e. pdf (Last accessed: 13 February, 2018). 